\title{
Lung Disorders of Workers Exposed to Rush Smear Dust in China
}

\author{
Guo-Bing XIAO ${ }^{1 *}$, Kenji MORINAGA ${ }^{2 \dagger}$, Ren-Yuan WANG ${ }^{3}$, Lai-Rong XU ${ }^{4}$, Zao-Hua MA ${ }^{5}$, \\ Xing ZHANG ${ }^{6}$, Takumi KISHIMOTO ${ }^{7}$ and Norihiko KOHYAMA ${ }^{8}$
}

\author{
${ }^{1}$ Ningbo Municipal Agency for Public Health Inspection and Supervision, Ningbo 315010, P.R. China \\ ${ }^{2}$ National Institute of Industrial Health, Kawasaki 214-8585, Japan \\ ${ }^{3}$ Health Bureau of Ningbo, Ningbo, 315010, P.R. China \\ ${ }^{4}$ YinZhou district Center for Disease Control and Prevention, City of Ningbo, 315040, P.R. China \\ ${ }^{5}$ Institute of Occupational Medicine, Ningbo Municipal Center for Disease Control and Prevention, Ningbo, \\ 315010, P.R. China \\ ${ }^{6}$ The Academy of Medical Sciences, Zhejiang Province. Hangzhou, 310013, P.R. China \\ ${ }^{7}$ Okayama Rousai Hospital, Okayama, Japan \\ ${ }^{8}$ Toyo University, Tokyo, Japan
}

Received June 29, 2005 and accepted March 13, 2006

\begin{abstract}
The aim of this study was to evaluate the lung disorders of the workers exposed to rush smear dust. A cross sectional study was carried out on 1,709 current workers (788 male, 921 female) in 80 factories. All subjects were asked by questionnaire, and health examination including chest Xray was conducted for 661 workers in 35 factories. Lung function test was also examined for 119 non-smoking males among 661 subjects. Dust samplings were collected and total and respirable dust concentrations at 127 spots in 35 factories were measured. The geometric mean dust concentration in the workshops was up to $20.00 \mathrm{mg} / \mathrm{m}^{3}$, and the geometric mean respirable dust concentration reached $8.22 \mathrm{mg} / \mathrm{m}^{3}$. The mean quartz concentration of accumulated dust was $29.2 \%$. The prevalence of radiographic small opacities profusion category $>$ or $=1 / 0$, according to the ILO 1980 Classification System, was $2.6 \%$ among 661 employees. One worker was found to have pneumoconiotic findings of $2 / 2$ profusion accompanied with large opacity. The prevalence of pneumoconiosis $(1 / 0$ or more $)$ correlated with cumulative dust exposure $(r=0.192, p<0.0001)$. The similar relationship was found between the prevalence rate of cough or sputa and worksite dust concentration. In non-smokers, a positive association was found between the prevalence of cough and occupational exposure duration $(r=0.080, p=0.004)$. Approximately $19.3 \%$ and $34.5 \%$ of employees suffered from respiratory impairment for FVC and FEV1.0, respectively. This is the first report of "rush" pneumoconiosis in China. Rush mat workers were found to be at high risk for pneumoconiosis, a preventable disease. Our results showed a dose-response relationship between rush-mat dust level and the prevalence of pneumoconiosis. Similar relationship between the prevalence of cough and sputum and the work duration was found for non-smoking workers but not for smoking workers.
\end{abstract}

Keywords: Rush mat, Pneumoconiosis, Lung function, Dust, Silica

\footnotetext{
*To whom correspondence should be addressed. 'Present affiliation: National Institute of Occupational Safety and Health, Japan.
} 


\section{Introduction}

"Tatami" matting produced from rush is used in almost all households in Japan. In recent years, rush growth and tatami production has been extended to several other countries in Southeast Asia. Now, nearly half of matting is imported from China, and about $75 \%$ of its import is from Ningbo, Zhejiang province. Rush mat process has more than 20 years' history in China, which was introduced from Japan. Rush cultivating and processing began in 1980s in Ningbo. In 1999, the cultivating area reached 5,980 hectares, and exports of matting to Japan was 45,000 meters long. There are about 350 factories and 5,000 employees estimated in this area.

In order to prevent the mat color from fading of the tatami mat color and to increase its strength, fresh reaped rush is smeared with mud ${ }^{1-3)}$. During the process of drying, selection and weaving, workers are heavily exposed to the dust of dried mud. The dyeing dust contains $20-30 \%$ of free silica and therefore is a potential cause of pneumoconiosis. But the effect on workers exposed to the dust in China has not been explored. The aim of this study is to assess the current status of rush mat dust exposure in Chinese matting industries, and to assess the health effect of the exposed workers.

\section{Material and Methods}

\section{Survey design}

The study was conducted from June 1999 to December 2001 in a town of Zhejiang province. Factories to be studied were randomly drawn from local registered enterprises, and all employees of those factories were invited to participate in this study. In total, 80 factories participated in the study, and 1,709 respondents were examined, which corresponded $94 \%$ of total employees. Nearly half of those factories have less than 20 employees. A questionnaire on the detailed occupational history, respiratory symptoms, and smoking habit were asked to the subjects. A group of 661 current workers was randomly selected from 35 factories, and received the screening of PA chest $\mathrm{X}$ rays and other physical examination coupled with detailed occupational work histories about the intensity and characteristics of exposure to dust. A total of 119 non-smokers among 661 workers were also examined on lung function test.

\section{Dust sampling}

Dust samplings were collected by passive dust monitors according to the Chinese criteria method of dust measurement in the workplace (1). Total dusts were collected by ordinary dust sampler (total dust) (WUHANG Analytic Instrument
Factory FC-2 dust sampler, China). And the respirable dusts were collected by respirable dust sampler (WUHANG Analytic Instrument Factory, $\mathrm{CCH}-301$ respirable dust sampler, China) with the cellulose acetate filter using polyvinyl chloride. This technique conforms that the flow rate which in principle with the the BMRC criteria. Simultaneously digital dust monitor (Sibata, Model LD-1L) was also used. In factory A, respirable dust was also measured by digital counter which count $7 \mu \mathrm{m}$ and smaller dust. Simultaneously, dust was collected by ordinary sampler, and the count was adjusted by $\mathrm{K}$ value. Furthermore, we collected Sedimentation dust by brush from Factory A, B and C. Then, the sedimentation dust was separated by water sedimentation method to $7 \mu \mathrm{m}$ and smaller (respirable) and larger than 7 $\mu \mathrm{m}$. The contents of free silica in the sidementation dust and in respirable dusts were quantitatively analyzed by Xray diffraction and pyrophosphoric acid methods, respectively. The chemical compositions of dust were analyzed by X-ray diffraction (XRD) spectrometry. Cumulative of silica exposure of each employee was estimated by the concentration of each job categories and work duration.

\section{Pneumoconiosis diagnosis}

Two Chinese medical doctors and two Japanese physicians read these chest X-ray films independently, and classified them according to the Chinese Standard Classification of Pneumoconiosis, (GB5906-2000), and also to the ILO 1980 Classification of Radiographs ${ }^{4,5)}$. Chinese medical doctors have Chinese certificates of reading chest X-ray films of pneumoconiosis and two Japanese physicians are the members of the Pneumoconiosis Panel of the prefectural Labor Office in Japan. A case with more than 1/0 profusion of the ILO classification was defined as pneumoconiosis. If the classification of the radiographs was disagreed, most readers' score was adopted.

\section{Pulmonary function test}

Standardized measurements of lung function test using the Spirometry (Fukuda Sangyo ST-95, Japan) were conducted for 119 non-smoking males among 661 rush mat workers and a control of 193 male non-smokers who were working in the same city, but not in dusty working environment, which were employed in Machinery Manufacturing Plant. FVC defined as forced vital capacity (total amount air exhaled), and FEV1 as amount of air exhaled during the first second of forced expiration. Predicted values were calculated by the spirometer that based on race, gender, age, height, and weight. The abnormity was defined as actual 
value/predictive value $<80 \%$ for FVC and FEV1, and $<70 \%$ for FEV1 / FVC as actual value.

\section{Statistical analysis}

All results are analyzed using a SPSS 10.0 package of statistics using ANOVA, $\chi^{2}$ test, and multiple regressions.

\section{Results}

The rush mat processing began around 1978 in China. Now, Ningbo city is the major exporter of rush mat. The techniques of straw process are as follows; (1) fresh rush reaped is smeared with mud, and then dried. (2) The dried rush covered with a flimsy mud is stored in warehouse. (3) While carrying the dried rush bundles out of storage, selecting, cutting top and foot, and sorting rush root by length (selection). (4) A little wet is sprayed, and then rush is weaved by machines.

\section{Dust concentration in workplace}

Among various process of rush mat manufacturing, the highest respirable dust concentration was found in the rush dry, and its geometrical mean was $21.25 \mathrm{mg} / \mathrm{m}^{3}$ (Table 1).

\section{The chemical compositions of rush smear soil}

The rush mat smear soil was composed of various kinds of minerals, and result from crashing, rubbing, griddling and other process. $25.6 \%$ of quartz on average (15.8-35.6\%) in weight was found in the worksite sedimentation dust by pyrophosphoric acid analysis. The results of $\mathrm{x}$-ray diffraction were shown in Table 2. The main mineral phases of the dust were kaolinite, quartz, pyrophyllite, alunite, sericite, rutitle, illite and so on.

\section{The characteristics of workers}

The mean age was $36.6 \mathrm{yr}$ old for 788 male workers and $34.4 \mathrm{yr}$ old for 921 female workers (Table 3). Both male and female workers had mean less than 3 years' working duration, and the longest was about 17 yr. More than two thirds had less than 5 years' work duration, and only less than $3 \%$ had more than $10 \mathrm{yr}$ working history (Table 4). The distribution of the working duration for the 661 cohort was shown in Table 5.

\section{Smoking status}

Nearly half $(49.9 \%, 393 / 788)$ had current smoking habit, and 5.6\% (44/788) had ever smoking history. As there were few ever-smokers, we defined the smoker as those including ever-smokers and current smokers. However, nobody among 921 female workers had smoking habit.

Table 1. Dust concentration in workplace of rush mat process (geometric mean $\pm \mathrm{SD}, \mathrm{mg} / \mathrm{m}^{3}$ )

\begin{tabular}{lccllcr}
\hline \multirow{2}{*}{ Work title } & \multicolumn{2}{c}{ Total dust } & & \multicolumn{2}{c}{ Respirable dust } \\
\cline { 2 - 3 } \cline { 6 - 7 } & $\mathrm{n}$ & $G \pm G \mathrm{~s}$ & & $\mathrm{~N}$ & $G \pm G \mathrm{~s}$ \\
\hline Rush dry & 17 & $61.02 \pm 4.07$ & & 37 & $21.25 \pm 3.45$ \\
Rush selection & 26 & $31.05 \pm 2.78$ & & 24 & $10.19 \pm 2.28$ \\
Rush sorting & 7 & $41.34 \pm 2.62$ & & 18 & $11.53 \pm 1.64$ \\
Cutting off rush top and end & 8 & $51.89 \pm 3.22$ & & 19 & $8.28 \pm 2.32$ \\
Wiping off bad rush & 10 & $11.33 \pm 2.41$ & & 27 & $5.97 \pm 2.28$ \\
Rush mat weaving & 47 & $11.58 \pm 1.74$ & & 54 & $5.55 \pm 2.36$ \\
Rush mat mending & 9 & $9.81 \pm 1.50$ & & 10 & $3.56 \pm 1.68$ \\
Rush mat clearing & 0 & & & 11 & $5.53 \pm 1.32$ \\
Total & 127 & $20.00 \pm 3.14$ & & 200 & $8.38 \pm 2.75$ \\
\hline
\end{tabular}

Table 2. The contents of free silica in dust

\begin{tabular}{lccc}
\hline \multirow{2}{*}{ Worksite } & $<7 \mu \mathrm{m}$ ratio (\%) & \multicolumn{2}{c}{ Content of free silica (\%) } \\
\cline { 3 - 4 } & & Total dust & Respirable dust \\
\hline Factory A (respirable dust) & 37 & 42 & 12 \\
Factory A (sedimentation dust) & 33 & 46 & 11 \\
Factory B (sedimentation dust) & 23 & 53 & 16 \\
Factory C (sedimentation dust) & 17 & 47 & 16 \\
\hline
\end{tabular}


Table 3. The characteristics of 1,709 workers (mean \pm SD)

\begin{tabular}{lcccc}
\hline Gender & $\mathrm{n}$ & Age $(\mathrm{yr})$ & $\begin{array}{c}\text { Age at the first } \\
\text { employment }(\mathrm{yr})\end{array}$ & Work duration(yr) \\
\hline Male & 788 & $36.61 \pm 10.25(17.35-68.21)$ & $31.72 \pm 10.16(13.34-62.12)$ & $2.83 \pm 2.46(0.10-16.90)$ \\
Female & 921 & $34.22 \pm 8.23(17.18-67.22)$ & $29.31 \pm 8.06(13.67-64.04)$ & $2.59 \pm 2.16(0.10-16.50)$ \\
Total & 1709 & $35.32 \pm 9.29(17.18-68.21)$ & $30.42 \pm 9.16(13.34-64.04)$ & $2.70 \pm 2.31(0.10-16.90)$ \\
\hline
\end{tabular}

Table 4. Distribution of work duration

\begin{tabular}{lcccccccc}
\hline \multirow{2}{*}{$\begin{array}{l}\text { Work } \\
\text { duration }\end{array}$} & \multicolumn{2}{c}{ Male } & & \multicolumn{2}{c}{ Female } & & \multicolumn{2}{c}{ Total } \\
\cline { 2 - 3 } \cline { 9 - 10 } \cline { 9 - 10 } & $\mathrm{n}$ & $\%$ & & $\mathrm{n}$ & $\%$ & & $\mathrm{n}$ & $\%$ \\
\hline$<1$ & 137 & 17.4 & & 182 & 19.8 & & 319 & 18.7 \\
$1-$ & 524 & 66.5 & & 633 & 68.7 & & 1,157 & 67.7 \\
$5-$ & 104 & 13.2 & & 88 & 9.6 & & 192 & 11.2 \\
$10-$ & 23 & 2.9 & & 18 & 2.0 & & 41 & 2.4 \\
Total & 788 & 0.00 & & 921 & 0.00 & & 1,709 & 100 \\
\hline
\end{tabular}

Table 5. The age distribution of the 661 workers by sex

\begin{tabular}{|c|c|c|c|c|c|c|}
\hline \multirow{2}{*}{ Age } & \multicolumn{2}{|c|}{ Males } & \multicolumn{2}{|c|}{ Females } & \multicolumn{2}{|c|}{ Total } \\
\hline & $\mathrm{n}$ & $\%$ & $\mathrm{n}$ & $\%$ & $\mathrm{n}$ & $\%$ \\
\hline$<20$ & 6 & 1.72 & 11 & 3.53 & 17 & 2.57 \\
\hline $20-$ & 99 & 28.37 & 77 & 24.68 & 176 & 26.63 \\
\hline $30-$ & 119 & 34.10 & 133 & 42.63 & 252 & 38.12 \\
\hline $40-$ & 70 & 20.06 & 76 & 24.36 & 146 & 22.09 \\
\hline $50-$ & 50 & 14.33 & 14 & 4.49 & 64 & 9.68 \\
\hline $60-70$ & 5 & 1.43 & 1 & 0.32 & 6 & 0.91 \\
\hline Total & 349 & 100.00 & 312 & 100.00 & 661 & 100.00 \\
\hline
\end{tabular}

\section{Respiratory symptoms}

The prevalence of cough in male smokers was $26.5 \%$ (116/ 437), and that of sputum was $22.4 \%$ (98/437), which were significantly higher than those of male non-smokers $(16.2 \%$, $13.1 \%$, respectively). The prevalence of cough and sputum in female workers was 7.9\% (73/921), and 6.4\% (59/921), respectively. The prevalence rates of cough and sputum in non-smoker were low in workers with duration $<1 \mathrm{yr}$, but high in workers with duration $\geq 7 \mathrm{yr}$ (Table 6). $\chi^{2}$ for linear trend and Pearson's $\mathrm{R}$ between work duration and prevalence of cough in non-smokers (both sexes combined) were significant $\left(\chi^{2}=8.10, p=0.004\right.$; Peason's $\mathrm{R}=0.08, p=0.004$ ), but those of sputum in non-smokers and those of two symptoms in smokers were not.

Table 7 shows that the prevalence rates of two symptoms in non-smokers and smokers were low in management workers, but high in rush dry and selection workers of which workplaces shown high concentration of total and respirable dust (Table 1). $\chi^{2}$ for linear trend and Pearson's R between jobs and prevalence of cough in non-smokers, sputum in non-smokers, cough in smokers and sputum in smokers were significant (see to Table 7).

\section{Pulmonary function test}

Base on the results of FVC, $\mathrm{FEV}_{1.0}$, and $\mathrm{FEV}_{1.0} \%$, abnormity prevalence and scale were shown in Table 8 . Approximately $19.3 \%$ and $34.5 \%$ of employees suffered from respiratory impairment for $\mathrm{FVC}$ and $\mathrm{FEV}_{1.0}$, respectively.

\section{Chest radiographs}

A total 661 workers were received chest X-ray screening. Main work titles were selection, repairing, and storing in male, and weaver in female. After reading these films, we have found 17 cases with category $1 / 0$ or more. The prevalence of pneumoconiostic finding reached $2.57 \%$ (17/ 661). The mean age of these 17 cases was $37.67 \pm 8.28$ (22.2-50.0) yr, and mean work duration was $6.39 \pm 4.02$ (3.2-17.0) yr. Most of all cases revealed small rounded opacities as shape and size of type $\mathrm{p}$ in the upper and/or middle lung field. Only one case was found $2 / 2$, and several smaller nodules coalesced, and agglomerated in right upper lung field. The case is a selecting worker, with $30 \mathrm{yr}$ old and $6.0 \mathrm{yr}$ work duration (Figs. 1 and 2). All cases denied other dust work history. The prevalence of pneumoconiotic findings was related to work duration and work title (Table 9).

\section{Discussion}

Rush dyeing dust pneumoconiosis (defined as sendo-dust pneumoconiosis in Japanese literatures) is a pneumoconiosis caused by dust containing free silica in a very high degree of dispersion is seen in rush mat (tatami) workers. In the Japanese-language literature, it has been estimated that the incidence of pneumoconiosis in igusa mat workers is $>30 \%$. It has been found that the workers tend to acquire a relatively early stage of pneumoconiosis after approximately $20 \mathrm{yr}$ of dust exposure, 2). Yamawaki et al. (1998) reported the prevalence of pneumoconiosis with category $1 / 0$ or more was $19.6 \%$ for males and $34.6 \%$ for females, and found 4 cases ( 3 males, 1 female) with large opacities, those had 
Table 6. The relationship between prevalence of respiratory symptoms and working duration

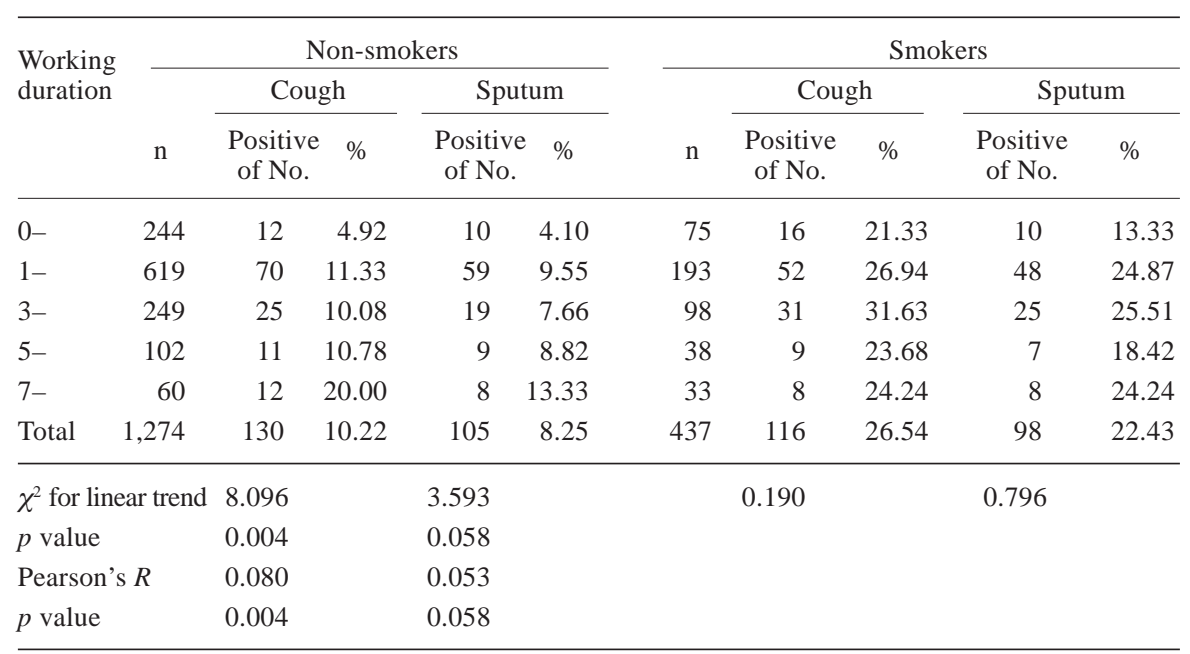

Table 7. The relationship between prevalence of respiratory symptoms and job title

\begin{tabular}{|c|c|c|c|c|c|c|c|c|c|c|}
\hline \multirow[t]{3}{*}{ Jobtitle } & \multicolumn{5}{|c|}{ Non-smokers } & \multicolumn{5}{|c|}{ Smokers } \\
\hline & \multirow[b]{2}{*}{$\mathrm{n}$} & \multicolumn{2}{|c|}{ Cough } & \multicolumn{2}{|c|}{ Sputum } & \multirow[b]{2}{*}{$\mathrm{n}$} & \multicolumn{2}{|c|}{ Cough } & \multicolumn{2}{|c|}{ Sputum } \\
\hline & & $\begin{array}{c}\text { Positive } \\
\text { of No. }\end{array}$ & $\%$ & $\begin{array}{c}\text { Positive } \\
\text { of No. }\end{array}$ & $\%$ & & $\begin{array}{c}\text { Positive } \\
\text { of No. }\end{array}$ & $\%$ & $\begin{array}{c}\text { Positive } \\
\text { of No. }\end{array}$ & $\%$ \\
\hline Manager & 99 & 6 & 6.1 & 4 & 4.0 & 28 & 4 & 14.29 & 3 & 10.71 \\
\hline Repairing & 94 & 11 & 11.7 & 11 & 11.7 & 83 & 9 & 10.84 & 6 & 7.23 \\
\hline Rush mat mending & 650 & 43 & 6.6 & 33 & 5.1 & 35 & 7 & 20.00 & 7 & 20.00 \\
\hline Rush mat weaving & 122 & 17 & 13.9 & 15 & 12.3 & 83 & 26 & 31.33 & 22 & 26.51 \\
\hline $\begin{array}{l}\text { Rush dry and } \\
\text { selection }\end{array}$ & 309 & 53 & 17.3 & 42 & 13.7 & 208 & 70 & 33.65 & 60 & 28.85 \\
\hline Total & 1,274 & 130 & 10.2 & 105 & 8.3 & 437 & 116 & 26.54 & 98 & 22.43 \\
\hline$\chi^{2}$ for linear trend & & 19.28 & & 14.71 & & & 17.96 & & 17.11 & \\
\hline$p$ value & & 0.001 & & 0.001 & & & 0.001 & & 0.001 & \\
\hline Pearson's $R$ & & 0.123 & & 0.108 & & & 0.203 & & 0.198 & \\
\hline$p$ value & & 0.001 & & 0.001 & & & 0.001 & & 0.001 & \\
\hline
\end{tabular}

Table 8. Abnormal frequency of ventilatory function in non-smokers

\begin{tabular}{|c|c|c|c|c|c|c|c|}
\hline \multirow[b]{2}{*}{ Group } & \multirow[b]{2}{*}{$\mathrm{n}$} & \multicolumn{2}{|c|}{ FVC abnormity } & \multicolumn{2}{|c|}{$\mathrm{FEV}_{1.0}$ abnormity } & \multicolumn{2}{|c|}{$\mathrm{FEV}_{1.0} \%$ abnormity } \\
\hline & & Case & $\begin{array}{c}\text { Prevalence } \\
(\%)\end{array}$ & Case & $\begin{array}{c}\text { Prevalence } \\
(\%)\end{array}$ & Case & $\begin{array}{c}\text { Prevalence } \\
(\%)\end{array}$ \\
\hline Exposed & 119 & 23 & $19.3 *$ & 41 & $34.5^{* * * *}$ & 2 & 1.7 \\
\hline Control & 193 & 21 & 10.9 & 32 & 16.6 & 4 & 2.1 \\
\hline Total & 312 & 44 & 14.1 & 73 & 23.4 & 6 & 1.9 \\
\hline
\end{tabular}

$*, * * * p<0.05, p<0.001 v s$. Control.

engaged for more than $28 \mathrm{yr}$ in $\operatorname{Japan}^{6}$. Yoshimoto et al. (1991) found a case with larger opacities who engaged for $20 \mathrm{yr}$ in rush mat process ${ }^{7}$. However, the health risk of rush mat process has not been known in China. In our study, we found the prevalence of category $1 / 0$ or more was $2.6 \%$ of the 661 employees. This is the first case of pneumoconiosis among rush mat workers in China. The prevalence of pneumoconiosis in China is lower than that in Japan, but the working duration for Chinese workers is quite short than that of Japanese workers. Our cases in Ningbo, China were 


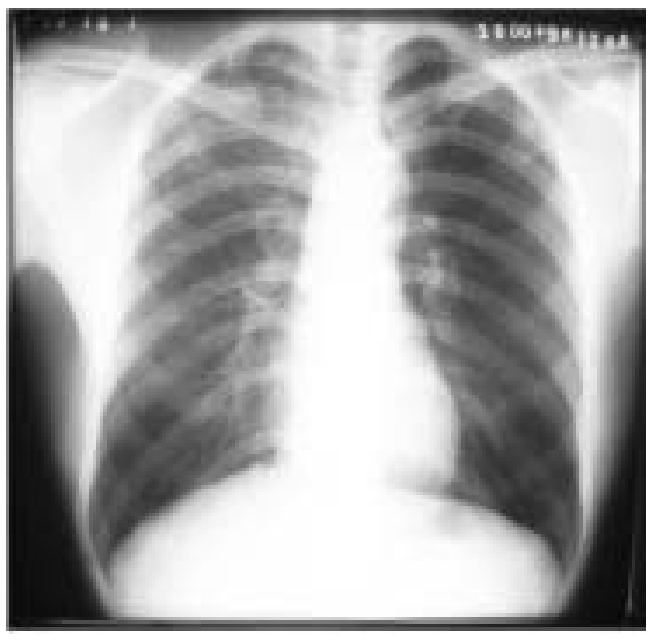

Fig. 1. Male, 31 yr old, employed in rush selection $6.0 \mathrm{yr}$. A conglomerate pneumoconiosis.

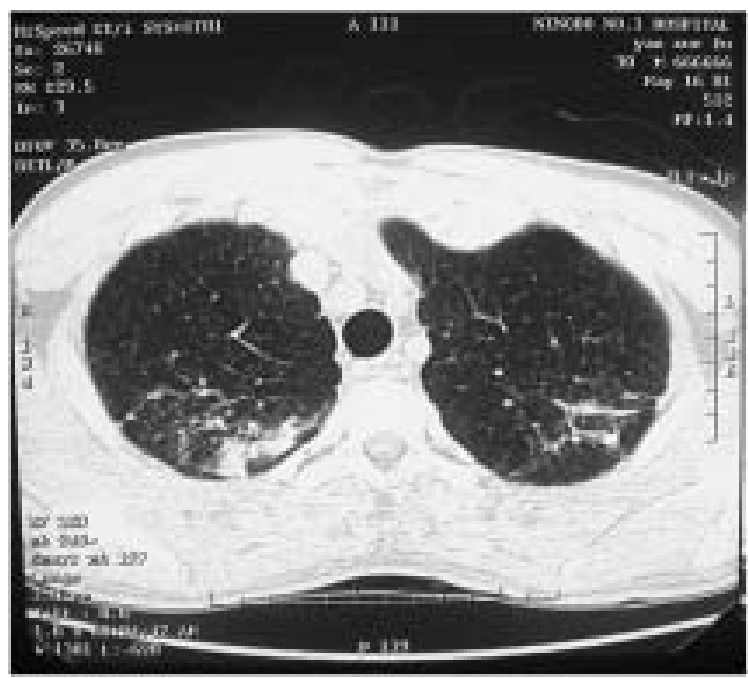

Fig. 2. The same case, HRCT revealed $10 \mathrm{~mm} \times 15 \mathrm{~mm}$ large opacities in right upper lung field.

all young ranging from 22.2 to $50.0 \mathrm{yr}$ old, and the work duration was very short ranging from 3.2 to $17.0 \mathrm{yr}$. The conglomerate pneumoconiosis case had only mean 6 years' work duration and $31 \mathrm{yr}$ old. Dust containing crystalline silica inhaled over prolonged periods promotes the formation of the classical nodules for a long time. The results show that the serious risk of pneumoconiosis in the rush mat process in the China setting.

The radiographic findings have been reported as consisting of small, rounded type-p and irregular type-s opacities, the latter type being generally dominant involving mainly the middle and lower lung zones ${ }^{2}$. Fujimoto reported that sendodust pneumoconiosis is a distinct form of pneumoconiosis
Table 9. Prevalence of small rounded opacities $1 / 0$ or more by cumulative silica exposure

\begin{tabular}{cccc}
\hline $\begin{array}{l}\text { Cumulative silica } \\
\text { exposure }\left(\mathrm{mg} / \mathrm{m}^{3}-\mathrm{yr}\right)^{*}\end{array}$ & $\mathrm{n}$ & $\begin{array}{l}\text { Positive no. of X-ray } \\
\text { categories } 1 / 0 \text { or more }\end{array}$ & $\begin{array}{l}\text { Prevalence } \\
\text { rate }(\%)\end{array}$ \\
\hline $0-$ & 156 & 0 & \\
$5-$ & 147 & 1 & 0.68 \\
$10-$ & 138 & 2 & 1.45 \\
$20-$ & 80 & 3 & 3.75 \\
$30-$ & 40 & 1 & 2.50 \\
$40-$ & 29 & 3 & 10.34 \\
$50-$ & 18 & 2 & 11.11 \\
$60-$ & 13 & 2 & 15.38 \\
$70-$ & 40 & 3 & 7.50 \\
Total & 661 & & 2.57 \\
\hline
\end{tabular}

$\chi^{2}$ for linear trend: $24.308, p$ value $<0.0001$

Pearson's $R$ : 0.192, $p$ value $<0.0001$

*cumulative silica exposure $=$ work duration $\times$ workplace respirable concentration

seen in tatami workers ${ }^{8}$. Although sendo contains free silica, typical silicotic nodules are not seen histologically, and progressive massive fibrosis, lymph node calcification, and lymphadenopathy are not seen on the radiograph or highresolution CT. The radiographic and high-resolution CT findings consist of small nodular opacities $<3 \mathrm{~mm}$ in diameter and bronchial and bronchiolar abnormalities. The dust contains $25.6 \%$ silica, it seems reasonable to speculate that the different appearance is related to the lower concentrations of silica, high density dispersion, and length of time performing tasks as compared to the patients with typical findings of silicosis. In our study, However, from the Xray founds, the density of small rounded opacities is a little light when compared to typical silicosis. The radiographic findings was similar to that in Japan. But, it is clear, one case was found $2 / 2$, and several smaller nodules coalesced, and agglomerated in right upper lung field in the present study. Kishimoto and Yamawaki reported cases of tatami rush pneumoconiosis with large opacities ${ }^{9}$, ${ }^{10}$. Consequently, it is reasonable to deduce that the rush mat dyeing dust can also damage the exposed worker by pneumoconiosis with large opacities.

Ueda et al. reported that in the process of drying and storing, approximately 70 to $80 \%$ of particles of floating dusts measure $<5 \mathrm{pm}$ in diameter. The workers are exposed to dense concentrations of sendo dust (50 to $100 \mathrm{mg} / \mathrm{m}^{3}$ ) for 1 to $3 \mathrm{~h} / \mathrm{d}$ in drying and storing, and continually exposed to low- density (1 to $5 \mathrm{mg} / \mathrm{m}^{3}$ ) sendo dust during the weaving process and relatively dense concentrated dust (15 to 25 $\mathrm{mg} / \mathrm{m}^{3}$ ) in the tatami storing process ${ }^{1)}$. In our study, some 
employees are exposed chronically to a rather low density rush dying dust during the weaving process $\left(3.76 \mathrm{mg} / \mathrm{m}^{3}\right)$, and some exposed to high dense concentrations during rush selection (respiratory dust concentration $10.79 \mathrm{mg} / \mathrm{m}^{3}$ ) and drying $\left(16.22 \mathrm{mg} / \mathrm{m}^{3}\right)$ for about $8-10 \mathrm{~h}$. Employees in rush process have high risk of getting pneumoconiosis because of high dust exposure compared to Japanese results.

The upper respiratory tract is a remarkably efficient filter, removing upwards of $90 \%$ of particles $>7 \mathrm{pm}$ in diameter ${ }^{11}$. Smaller particles may remain in suspension and be exhaled or may be deposited on the respiratory epithelium ${ }^{12}$. The dust accumulates predominately in the respiratory bronchioles and alveolar ducts. The results of the present study show a prevalence of work-related complaints among workers employed in the rush mat processing industry. The prevalence of cough and sputum was $10.22 \%, 8.25 \%$, respectively. Other symptom was rarely complained. From the difference of prevalence rate between non-smoker and smoker, we concluded that dust may partly account for the increased prevalence of respiratory symptoms among exposed workers.

It is well known that smoking is an independent contributor to declines in lung function ${ }^{13}$. Pulmonary function revealed mild functional impairment consistent with small airway obstruction and mild air trapping. In a 12 yr followup study, Swedish granite crushers exposed to mean cumulative respirable silica dust fraction of $7 \mathrm{mg}$ had a greater loss of FEV1 by $150 \mathrm{ml}(4.6 \%)$ and of FEV1/FVC\% by $3.2(5.4 \%)$ when compared to age and smoking matched unexposed controls ${ }^{14}$. In order to avoid the effect of smoking, we examined lung function for only non-smoking workers. Approximately $34.5 \%$ of employees suffered from respiratory impairment for FEV1.0. A weak dose-effect relationship between exposure to rush-mat dust and ventilatory function (FVC, FEV1) loss were found in nonsmokers. The relationship between radiographic hyperinflation and deterioration of pulmonary function was observed in silicaexposed workers ${ }^{15)}$. However, in the present study, the relationship can not be found.

The risk of pneumoconiosis among the workers exposed to dust containing silica depends on several factors such as crystalline silica content of the rush mat dust, effective equipment and tools used in the factory, length of time performing tasks, type and level of ventilation, work practices, housekeeping, and dust suppression methods. The rush smear mud is a mixture soil, which contains several minerals.

We noticed that the majority of overt exposures occurred in small and unregulated industrial settings. Intervention and supervision should be taken on in these plants.
(1) Cooperation. The process was imported from Japan. But, the related protective equipments and tools, and knowledge had not been imported simultaneously. The majority of overt exposures occurred in small and unregulated factories, and resulted in the fearful pneumoconiosis. Consequently, international cooperation in research achievement, technical support and equipment should be increased.

(2) All enterprises must be regulated, and small and unregulated plants should be eliminated. Reducing exposure to crystalline silica can be achieved through the use of wet processes and eliminating or severely restricting duration of dry process work. Local exhaust ventilation may be adapted to this industry. Mechanical operation may be substituted for manual selection process. The authors of this study found that the process could be substituted to mechanical operation in all factories.

(3) Given the high airborne concentrations of respirable silica and particulates generated during smear, selection and weaving, it should be recommended to employers that all exposed workers wear respiratory protection equipment until exposure controls were implemented. Develop and implement a written respiratory protection program for all dust operations.

(4) Medical examinations should be available to all workers who may be exposed to crystalline silica. Such examinations should occur before job placement and at least every one year thereafter. The examination should include PA chest X rays, internal routine check, and others.

(5) Good practice of housekeeping to prevent dust from re-suspending into the air. Dry sweep and usage of compressed air must be forbidden because these resuspend the dust and increases exposure to workers.

(6) Training of workers on the hazards of silica. Training should include information on health effects, work practices, personal protective equipment, and methods to reduce exposure to rush mat dust or silica.

\section{Conclusion}

The mineralogical phases of the dust were kaolinite, quartz, pyrophyllite, and mica, and the sedimentation dust contained nearly $26 \%$ (15-36\%) of quartz in weight. Rush mat workers were found to have a high risk for pneumoconiosis. Accelerated pneumoconiosis may be associated with heavy exposure to exiguous dust, long work time, lack of protective equipments, untrained workforces, smoking and others 
reasons. Dose-response relationship between the prevalence of cough and sputum and the work duration was found for non-smoking workers. The percentage of abnormity for FVC and FEV1 among the exposed workers was significantly greater than the controls (non-dust exposed). the MAC with $1 \mathrm{mg} / \mathrm{m}^{3}$ for respirable dust is not safe enough.

\section{Acknowledgements}

This research was partly funded by Japan-China Medical Association and Ningbo City Science Fund, P.R. China. The authors wish to express cordial thanks to Prof. You-Xin Liang, Prof. Tai-Yi JIN, and Prof. Xi-Peng JIN, Fudan University School of Public Health for their kind suggestions and constructive comments on the manuscript.

\section{References}

1) Ueda A, Futatsuka M, Ueda T, Arimatsu Y, Ueno T, Nagano M, Nomura S (1984) A follow-up study on the lung disorders of rush (igusa) farmers exposed to "sendo" dust. Sangyo Igaku 26, 32-44.

2) Fujii T (1970) Pneumoconiosis caused by "sendo" dust ainong rush-mat workers. Nippon Igaku Hoshasen Gakkai Zasshi 30, 266-86 (in Japanese with English abstract).

3) Hosoda Y, Ueda A, Fujii T (1991) Clay dye pneumoconiosis among rush mat workers. Semin Respir Med 12, 55-7.

4) Chinese GB Standards (1996) GB16225-1996, Health standard for respirable silica dust in the air of workplace. Beijing (in Chinese).

5) International Labor Organization (1980) Guidelines for the use of ILO international classification of radiographs of pneumoconioses. ILO, Geneva.

6) Yamawaki Y, Kuwahara K, Morinaga K, Kishimoto T, Sato Y, Kudo M, Ohyama M, Yokoyama K, Sera Y, Kohyama N (1998) "Rush (Igusa)" pneumoconiosis in Fukuama, Japan.
In: Advance in the Prevention of Respiratory Diseases. 1199202, Elsevier Science B.V., Amsterdam.

7) Yoshimoto S, Konishi H, Kawahara S, Tada A, Ejiri T, Sugano H, Matsuyama T, Nakajima M, Manabe T, Kibata M (1991) A case of rush dust (igusa-sendo) pneumoconiosis with a large conglomerate mass shadow. Jpn J Thoracic Dis 29, 1489-94.

8) Fujimoto K, Muller NL, Kato S, Terasaki H, Sadohara J, Rikimaru T, Hayabuchi N (2004) Pneumoconiosis in rush mat workers exposed to clay dye "sendo" dust clinical, radiologic, and histopathologic features in seven patients. Chest 125, 737-43.

9) Kishimoto T, Morinaga K, Yamawaki Y, Kawahara S, Matsushima T, Kohyama N (1999). Clinical evaluation of live cases of tatami rush pneumoconiosis with large opacities on chest X-ray. Jpn J Clin Radiol 44, 127-32 (in Japanese)

10) Yamawaki Y, Kishimoto T, Morinaga K, Kohyama N (2000). Epidemiological, occupational hygine, and mineralogical study on rush mat pneumoconiosis in Bingo area, Japan. Occup Health J 23, 31-7 (in Japanese).

11) Raabe OG (1984) Deposition and clearance of inhaled particles. In: Occupational lung disease, Gee JBL, Morgan WKC, Brooks SM (Eds.), 1-37, Raven Press, New York.

12) Davis GS, Calhouii WJ (1993) Occupational and environmental causes of interstitial lung disease. In: Interstitial lung disease, 2nd Ed., Schwarz MI, King TE Jr (Eds.), 179228, Mosby Year Book, St. Louis, MO.

13) Xu X, Dockery DW, Ware JH, Speizer FE, Ferris BG (1992) Effects of cigarette smoking on rate of loss of pulmonary function in adults: a longitudinal assessment. Am Rev Respir Dis 146, 1345-8.

14) Malmberg P, Hedenstrom H, Sundblad B-M (1993) Changes in lung function of granite crushers exposed to moderate highly silica concentrations: a 12 year follow up. Br J Ind Med 50, 726-31.

15) Wang X, Yano E (1999) Pulmonary dysfunction in silicaexposed workers: a relationship to radiographic signs of silicosis and emphysema. Am J Ind Med 36, 299-306. 